\title{
O Poder absoluto do Uno-bem e a eternidade do mal em Plotino
}

\author{
DEYSIELLE COSTA DAS CHAGAS *
}

* Pontifícia Universidade Católica do Rio de Janeiro (PUC-Rio)

Mestranda pelo Programa de Pós-Graduação em Filosofia

Bolsista CAPES
RESUMO O presente trabalho tem por objetivo apresentar uma análise acerca da relação de contrariedade, dentro da unidade do sistema cosmológico plotiniano, entre a hipóstase primordial e origem de todos os seres - o Uno-Bem (hén-agathós) - e a "realidade" que se apresenta como "outra do" Uno-Bem - o mal. Para tanto, utilizaremos o tratado Sobre a Origem dos Males (peri tou tina kaì póthen tà kakà) (Enéada I, 8 [51])), no qual Plotino descreve o mal (kakós) como a privação total do Bem e dos atributos originários dos seres verdadeiros, tendo como sua "substância" a matéria (hýle). Todavia, o mal "existe” por necessidade como aquilo que é contrário ao Bem, e, por ser o Bem eterno, este mal também não deixará de “existir”, não poderá ser “destruído”. Essa contrariedade - Bem-mal - constitui o mais alto grau de contrários e aponta para um problema fundamental da filosofia plotiniana, a saber, o poder absoluto do Uno-Bem. Compreender este "outro do" Uno-Bem e sua eternidade é essencial para a própria manutenção da unidade do sistema do nosso autor. É necessário também para afirmar, em todas as instâncias possíveis, inclusive temporal, a Sua perene capacidade de geração, sendo Ele fonte infinita de ser e que sempre alcança, ilumina e molda todos aqueles seres que lhe são posteriores - sejam eles inteligíveis (puros) ou sensíveis (mesclados de matéria/mal).

PalaVRaS-ChaVe Plotino; Uno-Bem; Mal; Matéria; Eternidade. 
EXISTE uma curiosa história relatada na única biografia de Plotino que nos foi herdada, na qual Porfirio, seu discípulo e biógrafo, nos conta que, das poucas coisas que Plotino falava de seu passado e de sua origem, ele sempre retomava esta em conversas frequentes no seu círculo:

Eis aqui, no entanto, o que nos contava ele (Plotino) mesmo por sua própria iniciativa em conversas frequentes conosco: que até o oitavo ano a partir do seu nascimento, embora ele já frequentasse a escola do gramático, costumava visitar sua mãe, e esta, descobrindo-lhe os seios, se dispunha a amamentar de boa vontade; porém, comentando uma vez alguém: “Que menino mais travesso!”, ele, cheio de vergonha, retirou-se. ${ }^{1}$

Esta passagem nos leva a refletir acerca da primeira grande lembrança de Plotino sobre um momento inicial de discernimento moral, acerca da relação da moralidade com os prazeres oferecidos pela corporeidade sensível. Como afirma Igal², este foi, provavelmente, como que um primeiro rito na trajetória de sua vida espiritual. Portanto, pensar a relação entre a corporeidade sensível e as disposições da alma, em Plotino, é condição necessária para compreender seu próprio sistema filosófico e percorrer seu trajeto místico.

Deste modo, trataremos aqui de um aspecto fundamental desta relação, qual seja, a natureza do mal que, segundo o neoplatônico, somente se dá e possui "existência" (se assim podemos chamar) nesta relação. Este tema resultou em um de seus últimos tratados - Sobre a origem dos males 3 (En. I 8 [51]) -, um dos mais problemáticos e discutidos na contemporaneidade por seus comentadores.

1 "He aquí, sin embargo, lo que nos contaba él mismo por propia iniciativa en frecuentes conversaciones con nosotros: que hasta el octavo año a partir de su nacimiento, pese a que acudía ya a la escuela del gramático, solía visitar a su nodriza y, descubriéndole los pechos, se disponía a mamar de buena gana; pero que, comentando una vez alguien: << iqué chiquillo más travieso!>>, lleno de vergüenza, se retrajo [...]”. PORFÍRIO, 2001, p. 132.

2 Cf. IGAL, 1972, p. 31-34.

3 Peri tou tina kaì póthen tà kakà. 


\section{A NATUREZA E “AS EXISTÊNCIAS” DO MAL}

Nas primeiras frases de seu tratado, o licopolitano nos apresenta os problemas que desenvolverá. O primeiro e o principal deles é “o que é o mal e qual a sua natureza?”, um questionamento de suma importância para um platônico e que, ao tentar solucioná-lo, Plotino toma um percurso peculiar. Primeiramente, ele afirma que nos é necessário definir de forma clara qual a natureza do Bem para assim compreender o mal. Isto já explicita a intencionalidade dada ao primeiro conceito de mal apresentado por Plotino, a saber, “o mal é o contrário do bem”5. Esta contrariedade, segundo Plotino, é o maior grau de todas as contrariedades existentes ${ }^{6}$, pois os “demais contrários são ou de mesma espécie ou de mesmo gênero e há algo em comum nas coisas que os recebem"7. Porém, esta contrariedade entre a natureza do Bem e a natureza do mal é de ordem prioritariamente ontológica, é a própria contrariedade do Ser e, neste caso em especial, a contrariedade do mal seria equivalente ao não-ser.

Consequentemente, Plotino nos apresenta sua segunda concepção de mal, aquilo que é "não-ser". Mas como podemos compreender isto uma vez que ele não-é-ser? Tomando o método adotado pelo nosso autor desde o início da investigação, devemos compreender o mal em relação ao Bem,

[...] da mesma maneira que consideramos a falta de medida em relação à medida, ou o ilimitado com respeito ao limitado, ou o que não tem forma com relação ao que tem, o que sempre é incompleto com respeito ao ser autárquico. Pois o mal é sempre indeterminado, nunca estável, por completo passivo, desejante e inteiramente pobre. E isto não é algo acidental, mas a própria substância do $\mathrm{mal}^{8}$.

4 “tí pot' estì tò kakòn kaì he kakoû phýsis próteron hýpotheînto". Cf. PLOTINO, 1966, p. 121. (En. I 8 [51], 1, 4-5.)

5 PLOTINO, 1966, p. 121 (En. I 8 [51], 1).

6 Cf. Ibid., p. 130-131 (En. I 8 [51], 6).

7 Ibid., p. 130 (En. I 8 [51], 6). Plotino possivelmente está se referindo aqui à explicação aristotélica do contrário como aquilo que é mais afastado num mesmo gênero. Cf. Cat. 6.6a17-18.

8 "de la misma manera que consideramos la falta de medida en relación a la medida, o lo ilimitado con respecto a lo limitado, o lo que no tiene forma en relación a lo que la tiene, o lo que siempre es incompleto con respecto al ser autárquico. Pues el mal es siempre indeterminado, nunca estable, por completo pasivo, desaseado y enteramente pobre. Y esto no es algo accidental sino la misma sustancia del mal (...)”. Ibid., p. 124 (En. I 8 [51], 3). 
O que é isto, portanto, que não tem em si mesmo nem a forma, nem a medida onde se ordenam as figuras e outras qualidades que a ele se acrescentam? O que seria isto que é a substância do mal (se é que o mal pode ter substância, como ressalta o próprio Plotino)? É a matéria sensível. É importante destacar desde logo que Plotino classifica duas noções de "existência” do mal: a) o mal em si mesmo e; b) o que tem mistura com ele.

A matéria, pois, é este mal em si mesmo ou este "não-ser". Ela, como afirma em seu tratado Sobre a Matéria, “é um sujeito indefinido porque não é forma” . Plotino ressalta, de maneira especial, que a compreensão deste sujeito que recebe a forma não pode ser a de um "lugar de atuação da alma”, pois ela não pode ter grandeza alguma - já que a grandeza se trata de uma forma que é anterior a matéria - e, consequentemente, ela não pode ter uma noção espacial. Portanto, também não se pode dizer que ela é substância dotada de qualidade ou predicações, um aquilo-de-que os seres sensíveis (aquilo que vem-a ser) se constituem, pois isto também pertence às formas que atribuem ser às realidades sensíveis. Toda a característica, qualidade e predicação dada ao ser sensível é conferida pelo princípio inteligível, inclusive a extensão. "Uma forma traz à matéria todas as propriedades desta; toda forma tem uma certa grandeza, que vem

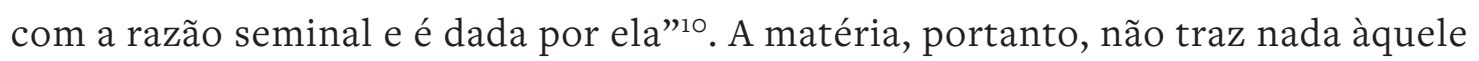
a quem ela serve de "receptáculo", exceto a sua total carência e necessidade de ser. Esta é, portanto, a natureza do mal/matéria para Plotino: uma total privação ou uma irrealidade. É neste sentido de total carência que o mal/matéria é um “não-ser”, pois, como nos afirma o licopolitano, “a privação é o mesmo que não-ser”11.

A segunda noção de "existência” do mal pertence a estes seres que vem-a-ser a partir da participação ou da "mistura" da matéria (o mal em si) nas formas que lhe advém por intermédio da alma, ou seja, a segunda noção de mal pertence aos seres sensíveis. Isto ocorre, afirma Plotino, porque quando a alma se mescla com a matéria, ela não é capaz de desenvolver todas as suas potencialidades, não encontra disposição para atuar ${ }^{12}$. Esta "alma debilitada", portanto, se torna geradora do devir e, juntamente

9 PLOTINO, 1972, p. 98 (En. II 4 [12], 6).

10 Ibid., p.101 (En. II, 4 [12], 8).

11 Ibid., p. 110 (En. II 4 [12], 14).

12 Cf. PLOTINO, 1966, p. 140-141 (En. I 8 [51], 14). 
com a matéria neste movimento de corrupção dos seres sensíveis, se torna causa destes males.

Contudo, é importante ressaltar que a alma em si não é causa geradora desses males, muito menos do mal em si. Seria absurdo admitir que a alma, que em sua natureza primeira pertence à hierarquia dos seres verdadeiros, trouxesse em sua natureza algum traço de um mal verdadeiramente existente, já que ele também viria da hierarquia das realidades primeiras (da realidade inteligível). Ou, em outro aspecto, também seria o mesmo que admitir que a alma é privada de bem e, portanto, de vida. Consequentemente, ela seria uma "alma inanimada” e isto resultaria num paradoxo. Assim sendo, “deverá considerar o bem como essencial à alma e o mal como algo que lhe é acidental"'33. Do mesmo modo como também ela não pode ser o Bem em si, mas que, através da virtude, conduz e participa do Bem, assim também, através da disposição viciosa, afasta-se deste mesmo Bem e aproxima-se da carência ou do mal.

Neste ponto, seguindo o caminho contrário ao proposto pelo nosso filósofo, precisamos então investigar a natureza do Bem para que, por aproximação, possamos ter uma compreensão mais específica daquilo que lhe é privação, do mal dentro de suas duas noções de "existência”.

\section{A NATUREZA DO UNO-BEM E A ETERNIDADE DO MAL}

Plotino, ao elaborar seu projeto filosófico, atribui ao princípio da totalidade a simples unidade absoluta denominada Uno-Bem (hén-agathos). Essa é a primeira hipóstase de sua estrutura triádica da realidade inteligível e é a partir dela que ocorre o movimento de processão (próodos), movimento este que se inicia pelo Uno-Bem e se segue até a realidade múltipla. Este Uno-Bem apresenta três noções ou “características”14 principais em seus tratados, que são: a) a sua infinitude, b) a sua absoluta transcendência e c) a sua inefabilidade.

A primeira característica do Uno-Bem, a qual deteremos mais atenção, é a sua infinitude. Essa infinitude apresentada por Plotino não diz respeito a sua grandeza ou

13 Ibid., p. 138 (En. I 8 [51], 12).

14 Estas três características do Uno aqui apresentadas foram propostas por Giovanni Reale. Cf. REALE, 2014 p. 44-47. 
extensão ou qualquer noção ligada à espacialidade, mas diz respeito "um poder ao qual não cabe apontar limites"15. Ele é superabundante e, enquanto poder infinito, é atividade, uma força ativa e fonte da eterna iluminação dos seres ${ }^{16}$ que engendra tudo o que lhe é posterior e de que, por isso, todos eles dependem e desejam retornar. Ele é este princípio eterno que detém o poder absoluto dentro do sistema plotiniano, e nada que foi engendrado a partir dele o empobrece ou o condiciona, dada a sua perene e perpétua permanência.

Não é, tampouco, nada finito, porque o que poderia limitar-lhe? Nem é nada infinito, ao menos em sentido de grandeza, porque até onde deveria avançar? E o que poderia resultar disto que nada tem necessidade? No entanto, sua potência possui a infinitude, pois nunca poderia perder nada, já que os seres ao que nada falta existem graças a Ele. Possui a infinitude porque não é múltipla e porque não tem nada que o limite. ${ }^{17}$

A segunda característica do Uno-Bem é sua absoluta transcendência. Ele não pode ser nenhuma das coisas pois é o princípio de tudo, logo ele deve estar acima do Ser e deve estar para além do Pensar. O Uno-Bem não conhece e nem desconhece nada, pois ele está em si mesmo e, consequentemente, não necessita pensar a si mesmo. Neste caso, há uma relativização da ontologia, pois Plotino não trata mais de uma metafísica do ser, mas poderíamos dizer que se trata de uma "henologia", ou seja, uma metafísica da unidade ou do Uno-Bem como princípio primeiro de todo $\operatorname{ser}^{18}$.

Pois, não sendo nenhuma das coisas, unicamente poderia dizer que está mais além delas. Porém, estas coisas são os seres e o Ser, o qual se quer indicar que seja algo determinado - porque nada se afirma d'Ele -, mas que se diz seu nome, expressando tão somente o que não-é. ${ }^{19}$

15 PLOTINO, 1967b, p. 397 (En VI 9 [8], 6).

16 Cf. PLOTINO, 1972, p. 148 (En. II 9 [33], 3).

17 "No es tampoco nada finito, porque ¿qué es lo que podría limitarle? Ni es nada infinito, al menos en el sentido de la magnitud, porque ¿hacia dónde debería avanzar? ¿Y qué podría resultar de esto, si de nada tiene necesidad? Sin embargo, su potencia posee la infinitud, porque nunca podría echar nada de menos, ya que los seres a los que nada falta existen gracias a El. Posee la infinitud porque no es múltiple y porque no tiene nada que lo limite." PLOTINO, 1967a, p. 138(En. V 5 [32], 10-11).

18 Cf. BEZERRA, 2006, p. 63-66.

19 "Porque, no siendo ninguna de las cosas, únicamente podría decirse que está más allá de ellas. Pero estas cosas son los seres y el ser, lo cual quiere decir que está más allá del ser. Con lo cual no se quiere indicar 
Esse "não-ser" atribuído ao Uno-Bem não significa que ele seja "nada em absoluto", mas que ele não pode ser algo em particular e nada pode defini-lo, denominá-lo. Negar a possibilidade de predicação é buscar, desde o âmbito da linguagem, a absoluta transcendência do Uno-Bem. Como Ele está acima de todo ser e todo pensamento, consequentemente também está para além da linguagem ${ }^{20}$. Essa é a terceira característica do Uno-Bem: a sua inefabilidade ${ }^{21}$. Tal afirmação dá margem até mesmo ao questionamento do próprio nome de "Uno-Bem” atribuído a Ele, que Plotino ressalva ser um nome convenientemente aplicado: "se a palavra uno e a coisa que designa tivessem algum sentido, ainda nos seria menos claro se carecesse de nome"22. Então essa inefabilidade do Uno-Bem é vista por dois pontos, primeiro a) o pensamento não dá conta de compreender o Uno-Bem e, segundo, b) o Uno-Bem, enquanto unidade-absoluta, é superior a toda a predicação. Portanto, fazer qualquer afirmação sobre o Uno-Bem objetiva apenas, como afirma Plotino, "mostrá-lo o melhor possível a nós mesmos”³.

Então, temos este Uno-Bem como princípio eterno que possui poder absoluto e que “não é ser”, e o qual tem como contrário o mal, que é esta privação e carência de ser e que, portanto, também "não é ser”. Plotino afirma que o mal “existe por necessidade, já que é preciso que haja um contrário ao Bem”"24. A “necessidade do mal” está em “ser" o término da sucessão de engendramentos, o último que nada mais produz, o mais distante e o que já não tem nada do $\mathrm{Bem}^{25}$. Mas isso nos leva a concluir que, por ser o Bem eterno, este mal também não deixará de “existir” ou podemos dizer,

que sea algo determinado - porque nada se afirma de El-, sino que se dice su nombre, expresando tan sólo lo que no es". PLOTINO, 1967a, p. 130 (En. V 5 [32], 6).

20 "[...] quando o filósofo (Plotino) nega a possibilidade de predicação, em verdade busca fundamentar, desde o ponto de vista da linguagem, a completa transcendência daquele que está por cima de toda a predicação e inteleç̧ão". BEZERRA, 2006, p. 68.

21 Aqui perceberemos componentes claros que fundamentam o que ficou conhecido na mística cristã como Teologia Negativa, mas com suas devidas particularidades. Como afirma REIS (2013, p. 77): “a própria expressão Teologia Negativa, que designa o método para se falar sobre Deus, ou princípio supremo (o próprio Plotino utiliza pouco o termo theós para falar do Uno), já seria uma expressão tendenciosa, na medida em que até o termo Deus deve ser negado daquilo que é absolutamente simples: 0 primeiro princípio não é nem o Diabo, nem Deus. Convém lembrar que mesmo o conceito de Deus é um conceito entre outros e deve, assim, também ser negado".

22 PLOTINO, 1967a, p. 131 (En. V 5 [32], 6).

23 PLOTINO, 1972, p. 144 (En. II 9 [33] 1).

24 PLOTINO, 1966, p. 129 (En. I 8 [51], 6).

25 Ibid., p. 133 (En. I 8 [51], 7). 
utilizando as palavras do próprio autor, “o mal não será destruído”26 e o que nos resta então é fugir dele.

Aqui, então, nos deparamos com uma aparente paradoxalidade do nosso autor. Como podemos admitir a eternidade ou a "não destruição" do mal, dentro da unidade dessa ordenação cosmológica, sem “colocar em xeque” o poder absoluto daquele princípio que é fonte inesgotável e eterna do Ser?

Há um outro fator que elucida ainda mais esse complexo problema. Como bem observa Narbone, existe um “salto" de um estado passivo do mal/matéria, enquanto pura privação, para um estado ativo que é capaz, inclusive, de afetar o desenvolvimento da potencialidade da alma que lhe envolve e debilita-la. Este "poder" poderia reforçar ainda mais o questionamento, em certa medida, da “eficácia” do poder absoluto do Uno-Bem:

O estatuto evidentemente ativo da matéria na produção do mal é evidenciado pelas duas passagens citadas $[$ En. I 8 [51 $]$ 4, 12-22/ 8,11-20]. No mesmo tratado Plotino indica ainda que a matéria obscurece e enfraquece a iluminação provinda da alma, que entrava seus poderes ao tomar posse do lugar ocupado pela alma, e que torna mal aquilo que ela recebe como uma espécie do voo. Como explicar essa mudança de atitude, esse novo poder conferido à matéria, ou melhor, à matéria como mal em I $8[51] ?^{27}$

\section{O PODER ABSOLUTO DO UNO-BEM}

Para compreender uma possível "saída” dada a este aparente paradoxo entre a eternidade do mal e poder absoluto do Bem devemos, antes de mais nada, salientar que o “não-ser” do mal/matéria é oposto ao "não-ser” do Uno-Bem. Enquanto o mal/matéria é, como foi dito, a ausência de ser e está abaixo dele ${ }^{28}$, o Uno é, como descrito acima, fonte inesgotável do Ser e está para além dele. O “não-ser” do mal/matéria é, dentro da perspectiva ontológica, como que desprovido de função no ser, como algo que não é e não pode vir-a-ser por si mesmo. Esta noção tem consequências dentro da perspectiva cosmológica do sistema filosófico plotiniano, pois o mal/matéria é visto

26 Ibid., p. 132 (En. I 8 [51], 7).

27 NARBONE, 2014, p. 127-128.

28 "[...] la materia tiene el ser antes de ella; no es realmente el ser, sino algo distinto del ser y que se encuentra por debajo de él” PLOTINO, 1972, p. 114 (En. II 4 [12], 16). 
como aquele que nada produz, mas, ao mesmo tempo, sua função “é ser” condição de possibilidade da produção dos seres sensíveis.

Não devemos, neste caso, simplificar de maneira apressada a noção de "não-ser" do mal/matéria para Plotino. Pois, ele não concebe este "não-ser" da matéria como o nada absoluto, mas "algo diferente do ser" ou a parte da alteridade ${ }^{29}$ que se opõe de maneira específica "aos seres por excelência, isto é, às razões formais"30. Mas essa oposição não possui um caráter de anulação ou destruição mútua. Quando a forma e a matéria se relacionam, a matéria não destrói as formas e todas as qualidades que lhe advém e, também, a matéria não é destruída, pois sua função de receptáculo depende da disposição contínua enquanto privação para que os seres sensíveis venham a ser.

Plotino, ao afirmar a eternidade do mal/matéria, não o condiciona necessariamente a eterna ausência de participação no Bem através da forma que lhe alcança, mas, como ele explicita em seu tratado Sobre as dificuldades acerca da Alma ${ }^{11}$

[...] tanto a entrada da alma no corpo como a ação de dar-lhe vida tem para nós um fim ilustrativo e de esclarecimento de nossa mente; porque é claro que este universo nunca careceu de alma, nem pôde existir em nenhum momento, estando a alma ausente dele, já que, tampouco, existiu uma matéria carente de ordem..$^{32}$

Portanto, afirmar a eternidade do mal/matéria não é contrariar o poder absoluto do Uno-Bem, mas é reafirmar este poder absoluto do Uno-Bem enquanto fonte inesgotável do Ser. Admitir isso é reforçar - desde aquela possibilidade mais remota - a capacidade potencial infinita de geração e engendramento que está Naquele que é absoluto contrário do mal/matéria e que alcança até o que seria Sua privação radical.

29 Aqui Plotino provavelmente se fundamenta na concepção de "não-ser" enquanto alteridade apresentada no diálogo O Sofista de Platão. "[Hóspede de Eléia] Sempre que dizemos não ser, não dizemos algo contrário ao ser, mas apenas outro”. PLATÃO, 2011, p. 240 (257b).

30 PLOTINO, 1972, p. 111 (En. II 4 [12],14).

31 Perì psikhês aporiôn prôton.

32 "[...] tanto la entrada del alma en el cuerpo como la acción de darle vida tiene para nosotros en fin ilustrativo y de esclarecimiento de nuestra mente; porque es claro que este universo nunca ha carecido de alma, ni ha podido existir en ningún momento, estando el alma ausente de él, ya que tampoco ha existido una materia carente de orden". PLOTINO, 1973b, p. 71 (En. IV 3, 9). 
Schwyzer nos aponta um caminho possível para a interpretação desta complexa faceta da teoria plotiniana. Ele afirma que

[a matéria] é o polo oposto do Uno; em relação ao Ser, é o polo oposto em relação ao Intelecto, mas, para ambos, não no sentido em que seria uma grandeza negativa e uma contra-potência. Matematicamente falando, seria possível reduzir essa matéria ao valor de zero. ${ }^{33}$

Comparar o mal/matéria ao zero matemático é bem ilustrar, metaforicamente, o semelhante papel que ambos têm em seus sistemas: o "nada" que "existe" eternamente. Ambos são aqueles que nada somam, que nada geram, mas que são condições de possibilidade da existência de seres enquanto privações. Já o Uno-Bem é “a realidade da qual tudo depende e a que aspiram também todos os seres, pois é seu princípio e aquilo que precisamente lhes falta" 34 .

Desse modo, temos aqui uma possível de solução para o nosso paradoxo. Mesmo admitindo (aparentemente) um “princípio ativo” do mal/matéria relatado por Plotino em seu tratado (En. I 8 [51]), ainda sim isto não “impediria”, nem muito menos contrariaria a atuação onipotente do Uno-Bem. Como bem analisa Narbone,

Plotino, como é sabido, crê firmemente na existência do Bem e em sua onipotência. Mas, de igual modo, crê na necessidade de um princípio verdadeiro e autônomo do mal, na medida em que crê na existência real do mal no mundo. Com efeito, se eles não podem ser referidos a um princípio próprio, os males permanecem sob a dependência do Bem, e isso em duplo sentido: primeiro, porque dele derivam ontologicamente, visto ser ele o único princípio de produção; em seguida, porque permanecem submetidos a ele axiologicamente, de modo que o mal reside simplesmente na diversidade, o mundo sensível, regido pelo Bem, teria então como único defeito - sem dele ter a responsabilidade não ser “uno".35

Se também adotarmos esta análise veremos, portanto, que Plotino, de uma maneira primorosa, não somente consegue manter características essenciais de cada elemento de seu sistema intactos, como também os entrelaça de uma maneira tal que o que parecia ser completamente impossível conceber dentro de um mesmo sistema acaba

33 SCHWYZER, 1973, p. 277, apud. NARBONE, 2014, p. 128.

34 PLOTINO, 1966, p. 122 (En. I 8 [51], 2).

35 NARBONE, 2014, p. 131. 
por revelar-se possível. Ainda mais, não se revela somente possível, mas, acima de tudo, Plotino também torna necessária esta relação entre esses elementos para reafirmar, em todos os aspectos, as características primordiais de cada um deles dentro de seu sistema filosófico.

\section{REFERÊNCIAS BIBLIOGRÁFICAS}

- PRIMÁRIAS:

PLOTINO. Eneada Primera. Trad. Jose Antonio Miguez. Buenos Aires: Aguilar, 1966. . Eneada Segunda. Trad. Jose Antonio Miguez. Buenos Aires: Aguilar, 1972. . Eneada Tercera. Trad. Jose Antonio Miguez. Buenos Aires: Aguilar, 1973 a. . Eneada Cuarta. Trad. Jose Antonio Miguez. Buenos Aires: Aguilar, 1973b. . Eneada Quinta. Trad. Jose Antonio Miguez. Buenos Aires: Aguilar, 1967a. . Eneada Sexta. Trad. Jose Antonio Miguez. Buenos Aires: Aguilar, $1967 \mathrm{~b}$.

\section{- SECUNDÁRIAS (CITADAS E CONSULTADAS):}

BEZERRA, Cícero C. Compreender Plotino e Proclo. Petrópolis: Vozes, 2006.

IGAL, Jesús. La cronologia de la Vida de Plotino de Porfirio. Bilbao: Universidad de Deusto, 1972.

NARBONNE. A Metafísica de Plotino. Trad. Mauricio Pagotto Marsola. São Paulo: Paulus, 2014 . Les deux matières [Ennéade II, 4 (12)]. Paris: J. Vrin, 1993.

O'BRIEN, Denis. Plotinus on the Making of Matter Part I: The Identity of Darkness. The International Journal of Platonic Tradition 5, 2011a.: 6-57.

Plotinus on the Making of Matter Part II: 'A Corpse Adorned' (En. II 4 [12] 5.18). The International Journal of Platonic Tradition 5, 2011b: 209-261. 
Plotinus on the Making of Matter Part III: The Essential Background. The International Journal of Platonic Tradition 6, 2012: 27-80.

PINHEIRO, Marcus R; AZAR FILHO, C. M. (Eds.) Neoplatonismo, mística e linguagem. Niterói: Ed. da UFF, 2013.

PINHEIRO, Marcus R. Plotino exegeta de Platão e Parmênides. Anais de Filosofia Clássica, v. 1, n. 2, 2007.

PLATÃO. O Sofista. Trad. Henrique Murachco, Juvino Maia Jr. e José Trindade Santos. Lisboa: Fundação Calouste Gulbenkian, 2011.

PORFÍRIO. Vida de Plotino. Trad. Jesús Igal. Madrid: Gredos, 2001.

REALE, Giovanni. Plotino e o Neoplatonismo. Trad. Henrique Cláudio de Lima Vaz e Marcelo Perine. $3^{\mathrm{a}}$ ed. São Paulo: Edições Loyola, 2014.

SCHWYZER, H-R. Zu Plotins Deutung de sogenannnten Platonischen Materie. Zetesis, 1973. 266-280. 